\title{
Revisiting the King's Cross Underground disaster with implications for modelling wildfire eruption
}

\author{
R.A. Edgar ${ }^{\text {a }}$, J.J. Sharples ${ }^{\text {a }}$ and H.S. Sidhu ${ }^{\text {a }}$ \\ ${ }^{a}$ Applied and Industrial Mathematics Research Group, \\ School of Physical, Environmental and Mathematical Sciences, UNSW Canberra, Australia. \\ Email: R.Edgar@adfa.edu.au
}

\begin{abstract}
In 1987 a fire engulfed the King's Cross Underground station complex, killing 31 people and seriously injuring more than 60 others. The extreme fire behaviour witnessed in this disaster was at odds with the fairly benign beginnings of the fire halfway down a wooden escalator trench. The first responders actually described the fire as like a 'small campfire' or 'cardboard box on fire'. The subsequent rapid development of the fire was unexpected, and at the time, unexplainable. In the following years, intensive investigation into this disaster identified a distinct physical mechanism that drove the extreme and rapid development of the fire: the 'trench effect'. The trench effect arises as a consequence of the geometry of the escalator trench and involves the flames and hot plume attaching to the bottom of the escalator trench. As part of the King's Cross fire investigation, detailed Computational Fluid Dynamic (CFD) analyses of the fire, which included the escalator configuration as well as the ticket hall, where most of the fatalities occurred, were performed. In the intervening years, CFD methods and implementation software have progressed significantly and so it is of interest to reconsider the scenario of the King's Cross fire in light of these new developments. It is also of interest to consider a number of similar scenarios that were not considered in the original CFD analyses. In this paper we use the ANSYS CFX package to provide a detailed numerical analysis of the heat-induced flows that arise in a number of scenarios related to the King's Cross fire. These include reanalysis of the original situation, in which the escalator trench is inclined at $30^{\circ}$, as well as cases with lower angles of inclination.
\end{abstract}

Simulation of the flows within the escalator trenches displayed marked differences in the flow characteristics depending on the inclination of the escalator trench. For the $10^{\circ}$ and $20^{\circ}$ tunnel inclinations the hot plume emanating from the modelled fire source separated from the floor of the elevator trench and advected up the tunnel in a distinctly turbulent manner. The separated and turbulent flow that manifested at lower tunnel inclinations was decidedly different to the simulated flow for the $30^{\circ}$ case. For the $30^{\circ}$ case the flow attached to the floor of the escalator trench and developed a distinctly laminar structure, which is consistent with findings of previous investigations into the King's Cross fire. Moreover the $30^{\circ}$ case gave rise to flows that were both faster moving: $7 \mathrm{~ms}^{-1}$ as opposed to $2 \mathrm{~ms}^{-1}$ for the $20^{\circ}$ case, as well as hotter: $430^{\circ} \mathrm{C}$ as opposed to $350^{\circ} \mathrm{C}$ for the $20^{\circ}$ case.

These results provide the first numerical verification of the existence of a threshold angle of inclination $\gamma^{*}$ that demarcates the separated, turbulent flow regime from the attached, laminar flow regime. As far as the authors are aware, the existence of this threshold angle of inclination has previously only been established in experimental work. Moreover, the numerical simulations presented indicate that $\gamma^{*} \in\left(20^{\circ}, 30^{\circ}\right)$, which is consistent with the value of $\gamma^{*} \approx 24^{\circ}-26^{\circ}$ determined from experiments.

The results presented have clear implications for the behaviour of wildfires burning in steep and confined terrain elements such as canyons and gullies. These implications are discussed.

Keywords: Eruptive fire, trench effect, fire hazard, slope, flame attachment 
R.A. Edgar, J.J. Sharples and H.S. Sidhu, Revisiting the King’s Cross Underground disaster ...

\section{INTRODUCTION}

On the 18th of November 1987 a fire at the King's Cross Underground Station in London exhibited behaviour that was both unexpected and disastrous, ultimately resulting in the loss of 31 lives and the grievous injury of many people including commuters, Underground staff and firefighters. The fire had ignited within a wooden escalator trench and burnt for approximately 15 minutes, during which firefighters assessed its size and behaviour and concluded that although it was a significant fire, there was nothing to suggest that it would rapidly develop. Indeed, the first responders actually described the fire as like a 'small campfire' or a 'cardboard box on fire' (Crossland, 1992). However, within an unexpectedly short amount of time the fire spread with extreme ferocity up the escalator trench and into the ticket hall and surrounding areas with tragic consequences. Investigations into the King's Cross fire revealed that the extreme fire growth was primarily caused by a distinct phenomenon, subsequently termed the 'trench effect', which caused the flames and combustion products to be confined and concentrated within the escalator trench below the balustrades. In a number of instances eyewitnesses and fire investigators described the fire behaviour associated with the trench effect as eruptive (Simcox et al., 1992; Moodie, 1992; Drysdale, 1992).

The term eruptive has also been used to describe certain instances of wildfire behaviour, which may have traditionally been referred to as blow-up or flare-up (Viegas, 2006). Such instances exemplify a very dangerous aspect of wildland fire behaviour; they pose a significant threat to the safety of wildland firefighters and complicate the broader problem of wildfire risk management in landscapes prone to their occurrence. Despite the seriousness of eruptive fire events, operational wildland fire spread models generally do not account for the possibility of eruptive fire behaviour and there is little in the literature devoted to obtaining a model that consistently describes the phenomenon. Recent exceptions include Viegas and Pita (2004); Viegas (2005, 2006); Dold and Zinoviev (2009); Sharples et al. (2010).

Studies addressing the incidence of eruptive fire behaviour have revealed that eruptive events are more likely to occur within specific terrain configurations, namely very steep slopes and canyons. In particular, the laboratory-scale experiments of Viegas and Pita (2004), who considered fire spread in different canyon-like configurations, indicated that eruptive fire behaviour occurred whenever the canyon was sufficiently steep or sufficiently closed. Similarly, the vast majority of eruptive wildfire events have taken place in canyons and on steep slopes. Thus, observations of eruptive fire behaviour have suggested the existence of a set of geometric precursors that are necessary for, or at least enhance the likelihood of, an eruptive event.

Interestingly, experimental and theoretical investigations conducted after the King's Cross fire also indicated that the existence of the trench effect was strongly dependent on the trench geometry. Indeed, the trench effect was found to only occur in trenches that were sufficiently steep, and to occur more readily in trenches that were more enclosed. The similar geometrical precursors required for extreme fire growth in a trench and eruptive behaviour of a wildfire in a canyon suggests that a landscape-scale trench effect may be a possible mechanism for eruptive wildfire spread.

In this paper we present simulations aimed at improving understanding of the physical mechanisms and the geometric precursors that drive eruptive fire behaviour. These simulations are based on the work of Simcox et al. (1992), who conducted computational fluid dynamics analyses of the pyrogenic flows within the escalator trench and ticket hall of the King's Cross station complex. In particular, Simcox et al. (1992) considered the escalator trench inclined at $30^{\circ}$ and found that the simulated flow distinctly confined itself to within the escalator trench, rather than rising upwards as might have been expected. This was the first indication of the trench effect, which was later confirmed in laboratory experiments (Dold and Zinoviev, 2009). However, the simulations conducted by Simcox et al. (1992) did not address cases where the escalator trench was inclined at angles less than $30^{\circ}$. In the ensuing experimental studies the angle of inclination was found to be of critical importance to the occurrence of the trench effect - indeed, these studies found that flame or plume attachment consistent with the trench effect only occurred within trenches inclined above a threshold angle of approximately $26^{\circ}$. Hence, in the absence of numerical simulations that treat inclinations less than $30^{\circ}$, it could be argued that the existence of a threshold angle of inclination necessary for the trench effect is yet to be verified in a mathematically rigorous way. Therefore the main aim of this paper is to remedy this situation and provide numerical simulations of the pyrogenic flows that would have resulted in the King's Cross escalator tunnels if they were inclined at shallower angles. A secondary aim is then to discuss the ramifications of the analytical results in the context of eruptive wildfire behaviour. 
R.A. Edgar, J.J. Sharples and H.S. Sidhu, Revisiting the King’s Cross Underground disaster ...

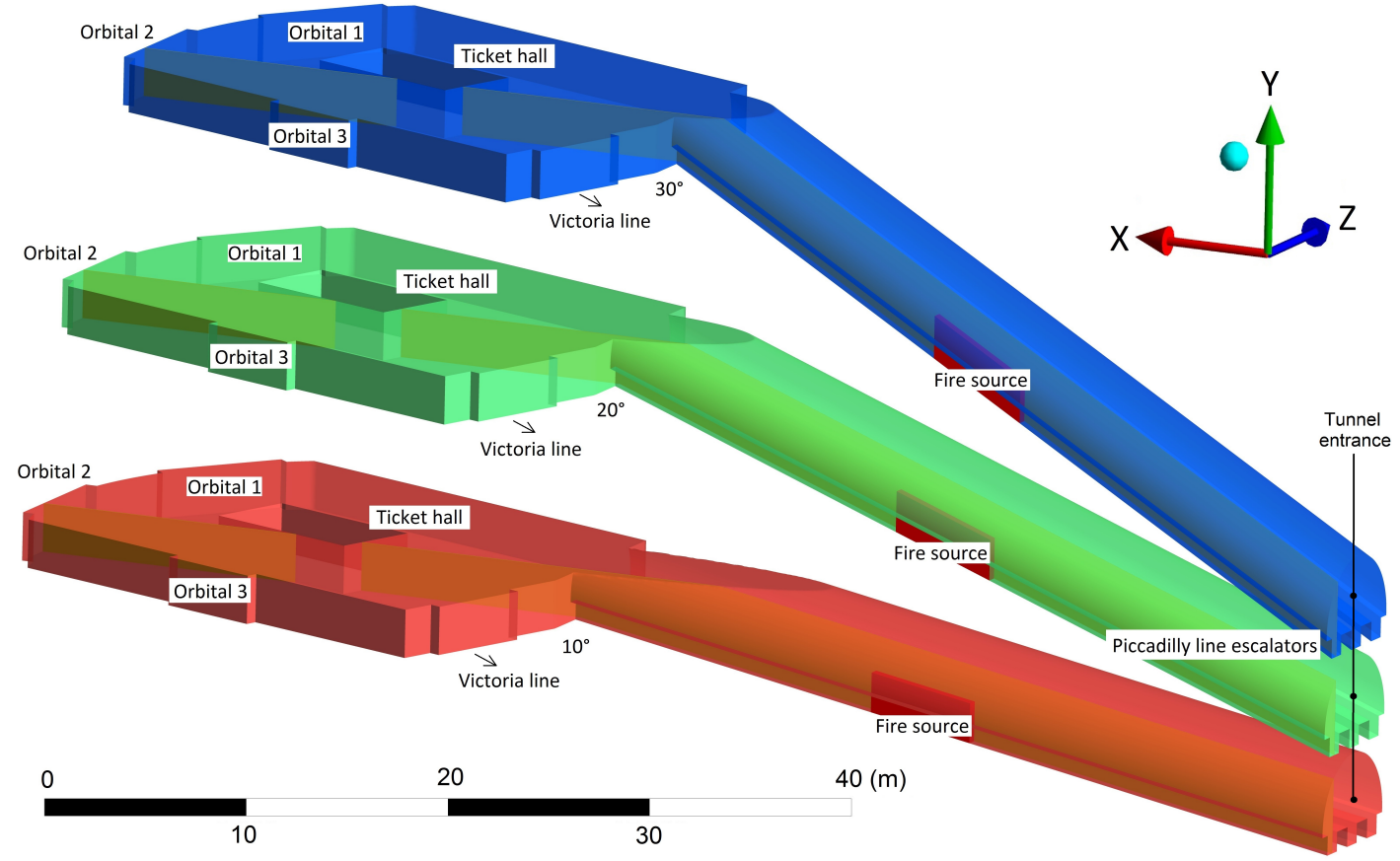

Figure 1: Geometry of King's Cross Station Picadilly Line escalators and ticket hall. The blue domain represents the existent station with tunnel escalators inclined at $30^{\circ}$, while the green and red domains are hypothetical with escalator inclinations of $20^{\circ}$ and $10^{\circ}$, respectively, considered in this study.

\section{COMPUTATIONAL FLUID DYNAMICS (CFD) MODEL}

The CFD package ANSYS CFX ver. 15, with its Scale Adaptive Simulation (SAS) turbulence model equations, was used to conduct scale resolving transient simulations of the King's Cross fire event. The SAS is a transient CFD model that makes use of the von Kármán length in turbulence scale equations to dynamically adjust to resolved structures in a unified-Reynolds Averaged Navier Stokes (uRANS) time stepping framework that switches to adopt LES-like behaviour in unsteady regions of flow fields (Menter, 2013). The Large Eddy Simulation (LES) relies on spatial filter refinement to derive the flow field's dependent variables (i.e. temperature, density and momentum) in lieu of the RANS decomposition of instantaneous flow variables into averaged and fluctuating components.

The three model domains considered are shown in Figure 1. They include the representative model of the King's Cross subway, shown with the Piccadilly line tunnel inclined at $30^{\circ}$, and two others that are identical except for the inclination of the $42 \mathrm{~m}$ long escalator tunnel, which has been modified to $20^{\circ}$ and $10^{\circ}$.

A summary of the simulation run conditions is provided in Table 1 and additional information is provided in the following paragraphs.

Table 1: Computation summary description.

\begin{tabular}{cccccccc}
\hline $\begin{array}{c}\text { Tunnel } \\
\text { angle }\end{array}$ & $\begin{array}{c}\text { Mesh } \\
\text { elements }\end{array}$ & Run & Model & $\begin{array}{c}\text { Run } \\
\text { time }\end{array}$ & $\begin{array}{c}\text { Energy } \\
(\mathrm{MW})\end{array}$ & $\begin{array}{c}\text { Energy } \\
\text { volume }\end{array}$ & Start condition \\
\hline $10^{\circ}$ & $4.3 \mathrm{M}$ & 1 & $\mathrm{SST}_{\mathrm{ss}}$ & $\mathrm{N} / \mathrm{A}$ & $\mathrm{N} / \mathrm{A}$ & $\mathrm{N} / \mathrm{A}$ & zero velocity \\
& & 2 & $\mathrm{SAS}_{\mathrm{tr}}$ & $36 \mathrm{~s}$ & 1.6 & 3.28 & $\begin{array}{c}\text { output of Run 1 } \\
\text { output of Run 2 }\end{array}$ \\
\hline $20^{\circ}$ & $4.5 \mathrm{M}$ & 1 & $\mathrm{SST}_{\mathrm{ss}}$ & $\mathrm{N} / \mathrm{A}$ & $\mathrm{N} / \mathrm{A}$ & $\mathrm{N} / \mathrm{A}$ & zero velocity \\
& & 2 & $\mathrm{SAS}_{\mathrm{tr}}$ & $36 \mathrm{~s}$ & 1.6 & 3.20 & output of Run 1 \\
& & 3 & $\mathrm{SAS}_{\mathrm{tr}}$ & $500 \mathrm{~s}$ & see Fig.2 & 11.73 & output of Run 2 \\
\hline $30^{\circ}$ & $4.2 \mathrm{M}$ & 1 & $\mathrm{SST}_{\mathrm{ss}}$ & $\mathrm{N} / \mathrm{A}$ & $\mathrm{N} / \mathrm{A}$ & $\mathrm{N} / \mathrm{A}$ & zero velocity \\
& & 2 & $\mathrm{SAS}_{\mathrm{tr}}$ & $36 \mathrm{~s}$ & 1.6 & 3.07 & output of Run 1 \\
& & 3 & $\mathrm{SAS}_{\mathrm{tr}}$ & $500 \mathrm{~s}$ & see Fig.2 & 11.28 & output of Run 2 \\
\hline
\end{tabular}


Geometry: The $30^{\circ}$ Piccadilly line tunnel numeric domain follows the physical description of the King's Cross Underground complex provided by Moodie (1992), see the blue volume in Figure 1. The tunnel width and ticket hall dimensions, not given explicitly, are estimated from sketches. The $840 \mathrm{~m}^{3}$ Piccadilly line tunnel has a semi-circular roof housing 3 escalators that run side by side $42 \mathrm{~m}$ up to the ticket hall with its volume of $1,330 \mathrm{~m}^{3}$. The ticket hall has 4 other domain openings - three opening boundaries for the King's Cross orbital passageway exits and one to the Victoria line tunnel escalators.

Additionally two hypothetical domains were developed to consider fire attachment in tunnels of $20^{\circ}$ and $10^{\circ}$ slope, see green and red volumes in Figure 1. The ticket hall height relative to the tunnel entrance is less in our hypothetical domains however the tunnel length needed to study fire attachment was preserved and required significantly less computational resources than otherwise.

Mesh: The spatial filter of scale resolving transient simulations is the mesh. An unstructured isotropic tetrahedral element mesh was chosen throughout the domain in order to allow turbulent flow(s) to develop without any distinction given to its direction. As a consequence the element count increased in proportion to the length scale $(l)$ cubed. Preference was given to refinement of the length scale of the filter over the number of wall inflation elements in order to resolve the thermal volumetric flow behaviour more effectively, since the turbulent kinetic energy of the model predominately arises from heat within the tunnel's volume rather than boundary layer stress (Reynolds number $(\mathrm{Rn}) \approx 10^{6}$ ). A total mesh element count of 4.3 million was obtained with $l=0.15 \mathrm{~m}^{3}$ in the tunnel and $l=0.4 \mathrm{~m}^{3}$ in the hall.

State equations: Air was taken to be an homogeneous mono-component fluid with pressure, density and temperature related by the ideal gas law. We considered viscosity and thermal capacity to be constants, i.e. independent of temperature, however when considered as temperature dependent variables using Sutherland's Law models (Poling et al., 2001) negligible difference in the simulated flows was observed.

Initial and boundary conditions: The air's initial velocity was set to $0 \mathrm{~ms}^{-1}$ at $t=0 \mathrm{~s}$ throughout the domain and allowed to adjust freely during the $500 \mathrm{~s}$ simulations according to specified boundary conditions and fire energy source driven buoyancy effects.

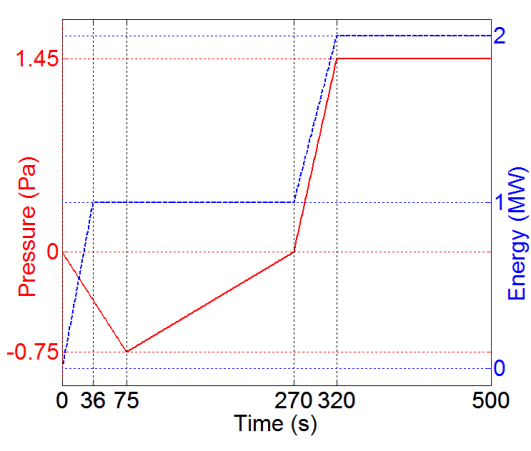

Figure 2: Picadilly Line tunnel lower entrance pressure boundary and energy of the fire source.

The Picadilly Line tunnel entrance is defined as an opening entrainment boundary with the time dependent relative opening pressure profile caused by the passage of trains through station tunnels shown in Figure 2. This pressure specification is the high fidelity King's Cross event representative profile determined and used by Simcox et al. (1992). The entrainment condition allows the direction of inflow to adjust so that gradient change is minimised locally. The opening pressure boundary condition, very importantly, adjusts pressure to limit the influx of momentum while a static pressure definition would encourage the tunnel's air to continuously accelerate as the simulation progressed in a physically unrealistic manner.

The Victoria Line tunnel entrance is defined as a $0.5 \mathrm{~ms}^{-1}$ inlet flow in the $30^{\circ}$ and $20^{\circ}$ tunnel simulations, while an outlet flow in the $10^{\circ}$ simulation. The latter was the level used by Simcox et al. (1992) to simulate the King's Cross incident. The remaining orbital passageway boundaries are defined as openings with a relative pressure of $0 \mathrm{~Pa}$.

Fire source: Four time dependent volumetric thermal energy source terms were introduced to simulate thermal energy and spread of fire within sub-volumes of the Picadilly Line tunnel. These four adjacent fire volumes lie in and above the trench of the left escalator (i.e. looking up the tunnel). They extend vertically from the escalator steps to $1 \mathrm{~m}$ above the handrail and run in the tunnel axis direction $22 \mathrm{~m}-26.5 \mathrm{~m}$ from the tunnel's lower entrance. The position of the fire volumes are shown in Figure 1.

The thermal energy levels used in the $20^{\circ}$ and $30^{\circ}$ tunnel transient simulations are shown in Figure 2 and consistent with the levels determined by Simcox et al. (1992) to be representative of the King's Cross fire conditions. Up until the so called flashover at $t=270 \mathrm{~s}$ only the two lower trench volumes (i.e. below the escalator rail height) are active. Since the flow velocity developed in the $10^{\circ}$ tunnel was lower, its fire energy was able to accumulate to physically unrealistic levels within the domain without clearing and a lower energy of the same profile but 0.8 the magnitude of that shown in Figure 2 was used. 
The volumetric gas production $(\Delta V)$ from conversion of solid combustibles ( $250 \mathrm{~g}$ of wood with $12 \%$ carbon) is estimated to be $0.3 \mathrm{~m}^{3} \mathrm{~s}^{-1}$, which is considered negligible within the $840 \mathrm{~m}^{3}$ tunnel given the wind speeds developed in the volume concerned.

\section{RESULTS}

Figure 3 shows output from the transient numerical simulations at the time of $500 \mathrm{~s}$; specifically the temperature and flow velocity fields in two planar sections of each tunnel angle domain are displayed. Temperature is represented by the colour scale, while the flow velocity is represented by cones aligned with the flow direction and whose size and shading indicate the flow speed. In a number of instances the cone tips appear to extend outside the domain but the centre of the cone's base within the domain is the location of the point associated with the velocities indicated.

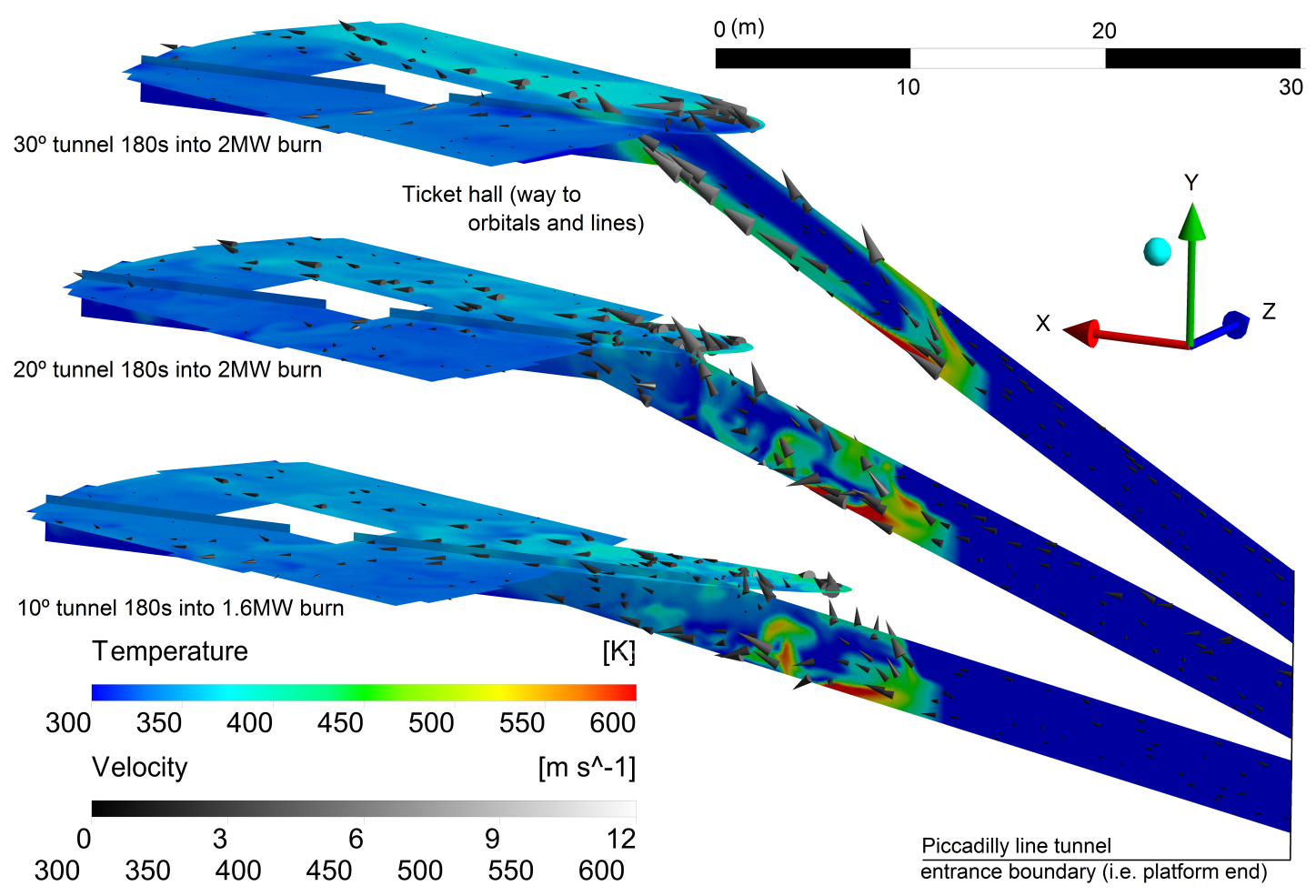

Figure 3: Simulated flows within the escalator trench and ticket hall for $10^{\circ}, 20^{\circ}$ and $30^{\circ}$ inclination cases at the end of run 3, $180 \mathrm{~s}$ after the peak energy level is attained. The colour theme represents temperature (K) while the flow velocity field is represented by conical arrows, with the size and shading of the arrows indicating flow speed $\left(\mathrm{ms}^{-1}\right)$.

The results indicate fundamental differences in the flow characteristics for the $30^{\circ}$ case and the $10^{\circ}$ and $20^{\circ}$ cases. In the $10^{\circ}$ and $20^{\circ}$ cases the flows are clearly separated (from the escalator trench floor) and possess a distinctly turbulent nature. This turbulent flow rises and spreads throughout the upper reaches of the tunnel. In contrast, the flow in the $30^{\circ}$ case manifests as a distinctly laminar flow, the majority of which is attached to the floor of the escalator trench. However, the height of the fire source volume has allowed a lesser component to escape from the escalator trench and attach to the tunnel roof. These results imply the existence of a threshold angle between $20^{\circ}$ and $30^{\circ}$, below which the flow up the tunnel separates from the tunnel floor and is inherently turbulent, and above which the flow transitions to an attached, laminar flow.

Figure 4 shows the temporal behaviour of transient flows for the three tunnel angles over the $500 \mathrm{~s}$ duration of the simulations. Specifically, flow velocity in the up-tunnel direction (Figure 4a) and temperature (Figure 4b) at a point located in the centre of the left escalator trench, $0.15 \mathrm{~m}$ above the floor and $3 \mathrm{~m}$ below the top of the escalator trench (ticket hall exit) are shown. For the $10^{\circ}$ case the flow velocity is close to zero for the entire $500 \mathrm{~s}$ simulation, which is fully consistent with the flow behaviour evident in Figure 3 . The plume rises almost immediately to the tunnel roof leaving the air above the fire, and in the lower parts of the escalator trench relatively unaffected. The flow velocity in the $20^{\circ}$ tunnel is considerably more turbulent, but its average 
reaches only about $2 \mathrm{~ms}^{-1}$ during the peak $2 \mathrm{MW}$ burn phase. The transient flow velocity in the $30^{\circ}$ tunnel, in contrast to the flows of the lower gradient tunnels, transitions from a turbulent to laminar flow, settling down to a comparatively higher average and more stable velocity of approximately $7 \mathrm{~ms}^{-1}$.

Similarly, the temperature time series in Figure $4 \mathrm{~b}$ indicate that for the $10^{\circ}$ case the temperature remains almost at ambient levels. The $20^{\circ}$ case displays distinctly turbulent characteristics, oscillating wildly between $300^{\circ} \mathrm{C}$ and $450^{\circ} \mathrm{C}$, with occasional peak values of around $500^{\circ} \mathrm{C}$, and a mean of approximately $370^{\circ} \mathrm{C}$. The temperature profile for the $30^{\circ}$ tunnel evolves to a much more stable configuration with a higher mean value of around $430^{\circ} \mathrm{C}$, which is consistent with the establishment of a fast moving laminar flow along the floor of the escalator trench.

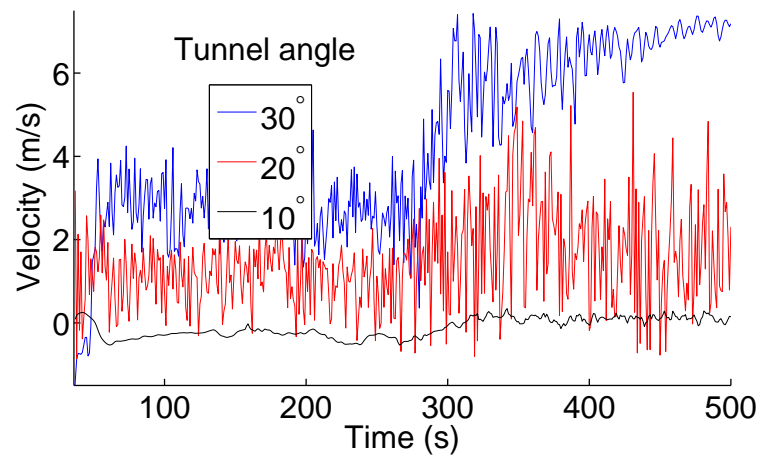

(a) Velocity all tunnels.

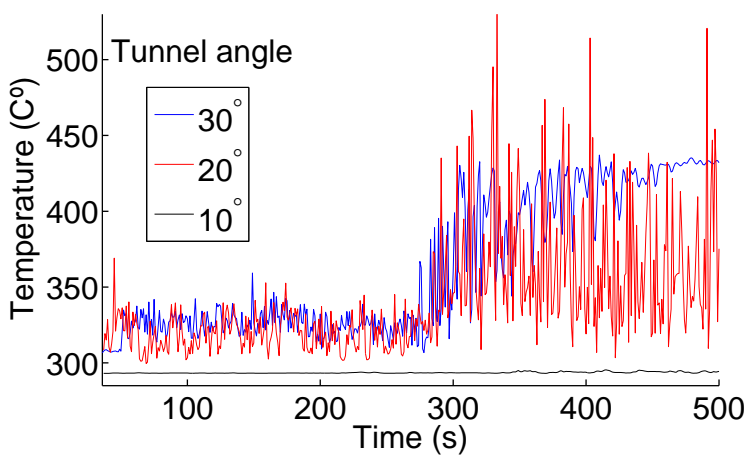

(b) Temperature all tunnels.

Figure 4: Transient flow variables at a central point in the left escalator trench of the tunnels considered and $3 \mathrm{~m}$ below the level of the respective hall.

\section{DISCUSSIONS AND CONCLUSIONS}

A CFD reanalysis of pyrogenic flows encountered during the King's Cross Underground fire was conducted using ANSYS CFX. In the years since the work of Simcox et al. (1992) there have been a number of improvements in CFD techniques and in computational power. These developments have enabled a much more detailed treatment of the problem. Only a few examples have been presented here - further features of the flow will be considered in ongoing research.

Our reanalysis also considered, for the first time, the flows that would have resulted if the escalator trenches within the King's Cross station complex were inclined at shallower angles (i.e. $10^{\circ}, 20^{\circ}$ ). The results of these simulations have provided the first numerical verification of the existence of a threshold angle of inclination associated with the trench effect. This threshold angle demarcates two flow regimes: the first characterised by separated, turbulent flow above slopes with inclinations less than the threshold angle; and the second characterised by attached, laminar flow above slopes with inclinations greater than the threshold angle. Based on the results presented above, we can conclude that this threshold angle $\gamma^{*}$ satisfies $20^{\circ}<\gamma^{*}<30^{\circ}$. This is entirely consistent with the experimental findings of Dold and Zinoviev (2009); Wu et al. (2000), which adduce that $\gamma^{*} \approx 24^{\circ}-26^{\circ}$. Further CFD analyses will be conducted to refine the findings presented above considering terrain topology and energy factors.

While the propagation of a fire front has not been autonomously modelled in our CFD model, there can be little doubt that once the attachment phenomena has taken effect, as is apparent for $30^{\circ}$ case i.e. with slope $>\gamma^{*}$, the resulting high-velocity and high-temperature flow will act to considerably enhance convective preheating of fuels, thereby increasing the rate of ignition of available fuel above the fire source, and as a consequence the rate of fire propagation up the slope. Indeed, the characteristics of fire behaviour driven by the trench effect, which have been reported in the past and confirmed here, bear a strong resemblance to the fire behaviour described in many blow-up fires and burn-over incidents. In particular, the rapid rates of spread and blasts of superheated air described in many burn-overs (see for example, (Butler et al., 1998; Viegas, 2009)) are consistent with the results of experimental and numerical work that lead to the discovery of the trench effect or flame attachment phenomenon. Such observations are also entirely consistent with the flow behaviour exhibited in our simulations (see Figures 3 and 4).

Flame attachment driven by the Coandă effect on the buoyant plume applies at a multitude of scales and so is a likely factor in eruptive wildfire occurrences. Indeed, eruptive fire incidents tend to occur almost exclu- 
R.A. Edgar, J.J. Sharples and H.S. Sidhu, Revisiting the King’s Cross Underground disaster ...

sively in landforms that satisfy the geometric prerequisites for flame attachment. Furthermore, the rapidity of the transition from a relatively low-intensity, slow spreading fire to a high-intensity, fast moving fire that is associated with the flame attachment phenomenon is consistent with the fact that in many burn-over incidents experienced firefighters are caught as if by surprise, with little time to reach safety. In addition, the sudden 'upslope wind change' that has been reported in many burn-over incidents on and above slopes is consistent with what would be experienced in the initial stages of plume attachment (see $30^{\circ}$ tunnel flow up trench in Figure 4).

The intricacies of terrain geometry and the impacts of fuel structure and highly variable winds in a wildland setting will all undoubtedly affect the onset of flame attachment, and hence eruptive fire behaviour. For example, slopes within the landscape are unlikely to possess a rectangular profile; rather they would be more likely to possess a V-shaped or parabolic profile. Further work will aim to extend the CFD simulations presented above to accommodate conditions that better resemble real landscapes by considering open boundary conditions above the slope (rather than an enclosed tunnel) and by incorporating changes in the profile geometry. These simulations will be complemented with targeted laboratory experiments.

\section{ACKNOWLEDGEMENT}

This research was funded under the Australian Research Council's Discovery Indigenous Scheme (IN140100011), and undertaken with the assistance of resources provided by the NCI National Facility at the Australian National University through the National Computational Merit Allocation Scheme supported by the Australian Government.

\section{REFERENCES}

Butler, B. W., R. A. Bartlette, L. S. Bradshaw, J. D. Cohen, P. L. Andrews, T. Putnam, R. J. Mangan, and H. Brown (1998). Fire behavior associated with the 1994 South Canyon fire on Storm King Mountain, Colorado. Technical report, USDA Forest Service.

Crossland, B. (1992). The King's Cross Underground fire and the setting up of the investigation. Fire Safety Journal 18(1), 3-11.

Dold, J. W. and A. Zinoviev (2009). Fire eruption through intensity and spread rate interaction mediated by flow attachment. Combustion Theory and Modelling 13(5), 763-793.

Drysdale, D. D. (1992). Special issue: The King's Cross fire. Fire Saftey Journal 18, 1-123.

Menter, F. R. (2013). Turbulence modelling for engineering flows. Technical report, ANSYS Inc.

Moodie, K. (1992). The King's Cross fire: damage assessment and overview of the technical investigation. Fire Safety Journal 18(1), 13 - 33.

Poling, B. E., J. M. Prausnitz, and J. P. O’Connell (2001). Properties of Gases and Liquids, Fifth Edition. McGraw Hill.

Sharples, J. J., A. M. Gill, and J. W. Dold (2010). The trench effect and eruptive wildfires: lessons from the King's Cross Underground disaster. Proceedings AFAC 2010.

Simcox, S., N. Wilkes, and I. Jones (1992). Computer simulation of the flows of hot gases from the fire at King's Cross Underground station. Fire Safety Journal 18(1), 49 - 73.

Viegas, D. (2009). Extreme forest fire behaviour and its potential damage to the environment and to society. In EGU General Assembly Conference Abstracts, Volume 11, pp. 13010.

Viegas, D. X. (2005). A mathematical model for forest fires blow-up. Combustion Science and Technology (177), 27-51.

Viegas, D. X. (2006). Parametric study of an eruptive fire behaviour model. International Journal of Wildland Fire 15(2), 169-177.

Viegas, D. X. and L. P. Pita (2004). Fire spread in canyons. International Journal of Wildland Fire 13(3), 253-274.

Wu, Y., H. Xing, and G. Atkinson (2000). Interaction of fire plume with inclined surface. Fire Safety Journal 35(4), 391-403. 